\title{
Concrete slab on elastic foundation under one axle load
}

\author{
Daniela Kuchárová ${ }^{1, *}$ and Gabriela Lajčáková ${ }^{1}$ \\ ${ }^{1}$ University of Žilina, Faculty of Civil Engineering, Univerzitná 8215/1, 01026 Žilina, Slovak \\ Republic
}

\begin{abstract}
The paper is dedicated to the dynamical analysis of an isolated concrete slab on an elastic foundation to moving load effect of one axle load. The computational models of one axle load and a slab are mathematically described by the system of ordinary differential equations. The equations of motion are solved numerically in the environment of program system MATLAB. The plate response and dynamic load are monitored at a certain speed and certain initial conditions, depending on the properties of the elastic subgrade.
\end{abstract}

\section{Introduction}

Reinforced concrete roadways are frequently used today [1]. Temporary road structures are often constructed as isolated prefabricated slabs. Smaller slabs are loaded with only one vehicle axle at a given time. The time courses of dynamic load and time courses of stress and strains at various conditions are needed for the proper design of the structure. The response of the slab to such a moving load is dependent on many factors - the speed of the vehicle, the initial conditions, the properties of the ground, the dimensions of the slab, the properties of the material, and so on. The computational model of one axle load and a computational model of a slab on an elastic foundation are created. Equations of motion are derived in the form of ordinary differential equations and they are solved numerically in the environment of MATLAB [2]. The influence of subgrade stiffness on slab vertical deflection and on dynamic load from the movement of one vehicle axle model is monitored. The results of the calculations are shown in the form of graphs supplemented with numerical data.

\section{Computational model of one vehicle axle and a slab}

\subsection{Computational model of one vehicle axle}

Computational model of one vehicle axle is created as two lumped mass model with three degrees of freedom, Fig. 1. The model has two masses and one mass-less degree of freedom. The functions $r_{i}(t),(i=1,2)$ describe the vibration of lumped masses of the model in the

\footnotetext{
*Corresponding author: daniela.kucharova@uniza.sk
} 
vertical direction. The contact force $F(t)$ corresponds to the mass-less degree of freedom. The model was already used in [3].

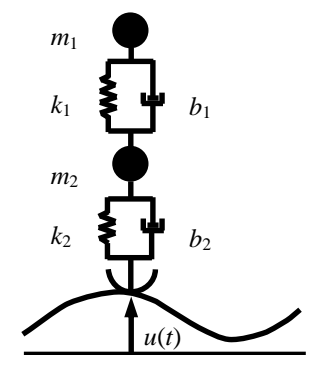

Fig. 1. Computational model of one vehicle axle.

The equations of motion for unknown functions $r_{i}(t)$ have the meaning of ordinary differential equations

$$
\begin{gathered}
\ddot{r}_{1}(t)=\left\{-k_{1} \cdot\left[r_{1}(t)-r_{2}(t)\right]-b_{1} \cdot\left[\dot{r}_{1}(t)-\dot{r}_{2}(t)\right]\right\} / m_{1} \\
\ddot{r}_{2}(t)=\left\{+k_{1} \cdot\left[r_{1}(t)-r_{2}(t)\right]-k_{2} \cdot\left[r_{2}(t)-h(t)\right]+b_{1} \cdot\left[\dot{r}_{1}(t)-\dot{r}_{2}(t)\right]-b_{2} \cdot\left[\dot{r}_{2}(t)-\dot{h}(t)\right]\right\} / m_{2}
\end{gathered}
$$

The expression for contact force is as follow

$$
F(t)=-G+k_{2} \cdot\left[r_{2}(t)-h(t)\right]+b_{2} \cdot\left[\dot{r}_{2}(t)-\dot{h}(t)\right]
$$

\subsection{Computational model of a slab}

The computational model of thin slabs on an elastic foundation was adopted [4]. The model was already used in [3]. The equation of motion of the slab oscillation has the form

$$
D\left(\frac{\partial^{4} w}{\partial x^{4}}+2 \frac{\partial^{4} w}{\partial x^{2} \partial y^{2}}+\frac{\partial^{4} w}{\partial y^{4}}\right)+K w+\mu \frac{\partial^{2} w}{\partial t^{2}}+2 \mu \omega_{b} \frac{\partial w}{\partial t}=F(t) \delta\left(x-x_{F}\right) \delta\left(y-y_{F}\right)
$$

This partial differential equation is solved by Fourier method. The assumption about the shape of bending plate of the slab $w_{0}(x, y)$ due to the load is adopted and the wanted function $w(x, y, t)$ describing the shape of bending plate of the slab in time $t$ is expressed as

$$
w(x, y, t)=q(t) w_{0}(x, y)
$$

where

$$
w_{0}(x, y)=\sin \frac{\pi x}{l_{x}} \sin \frac{\pi y}{l_{y}}
$$

The function $w_{0}(x, y)$ is the known function and it dependents on the coordinates $x, y$ only. The $q(t)$ function has the meaning of generalized Lagrange coordinate. It represents the proportionality coefficient between dynamic and static deflection in the time $t$. The meaning of other symbols is as follows: $D$ represents the slab stiffness $\left[\mathrm{Nm}^{2} / \mathrm{m}\right], K$ is the modulus of compressibility of elastic foundation $\left[\mathrm{N} / \mathrm{m}^{3}\right], \mu$ is the mass intensity of the slab $\left[\mathrm{kg} / \mathrm{m}^{2}\right], \omega_{b}$ is damping angular frequency $[\mathrm{rad} / \mathrm{s}]$. The resulting equation is obtained by substituting assumptions (4) and (5) in equation (3) and its further modification. In case of observing deflection in the middle of the slab $\left(x=l_{x} / 2\right.$ a $\left.y=l_{y} / 2\right)$ the resulting shape of (3) is 


$$
\begin{gathered}
\ddot{q}(t) \mu+\dot{q}(t) 2 \mu \omega_{b}+q(t) D\left[\left(\frac{\pi}{l_{x}}\right)^{4}+2\left(\frac{\pi}{l_{x}}\right)^{2}\left(\frac{\pi}{l_{y}}\right)^{2}+\left(\frac{\pi}{l_{y}}\right)^{4}+\frac{K}{D}\right]= \\
=\frac{4}{l_{x} l_{y}}\left\{-G_{2}+k_{2}\left[r_{2}(t)-u_{2}(t)-q(t) \sin \frac{\pi x_{F}}{l_{x}} \sin \frac{\pi y_{F}}{l_{y}}\right]+\right. \\
\left.+b_{2}\left[\dot{r}_{2}(t)-\dot{u}_{2}(t)-\dot{q}(t) \sin \frac{\pi x_{F}}{l_{x}} \sin \frac{\pi y_{F}}{l_{y}}-q(t)\left(\frac{\pi v}{l_{x}}\right) \cos \frac{\pi x_{F}}{l_{x}} \sin \frac{\pi y_{F}}{l_{y}}\right]\right\} \sin \frac{\pi x_{F}}{l_{x}} \sin \frac{\pi y_{F}}{l_{y}}
\end{gathered}
$$

In (6) $x_{F}=v \cdot t$ ( $v$ is speed of vehicle motion in $[\mathrm{m} / \mathrm{s}]$ and $t$ is time in $\left.[\mathrm{s}]\right)$.

\section{Numerical parameters of computational models}

Numerical parameters of vehicle computational model are as follows: $m_{1}=5860.1544 \mathrm{~kg}$; $m_{2}=910 \mathrm{~kg} ; k_{1}=287433 \mathrm{~N} / \mathrm{m} ; k_{2}=2550600 \mathrm{~N} / \mathrm{m} ; b_{1}=19228 \mathrm{~kg} / \mathrm{s} ; b_{2}=2746 \mathrm{~kg} / \mathrm{s} ; g=9.81$ $\mathrm{m} / \mathrm{s}^{2} ; G_{2}=\left(m_{1}+m_{2}\right) g=66415.214664 \mathrm{~N}$.

Composition of the pavement is shown on Fig. 2. The basic parameters of the slab model are: slab depth $h=0.24 \mathrm{~m}$; slab proportions in longitudinal and transverse direction $l_{x}=6.0$ $\mathrm{m} ; l_{y}=3.75 \mathrm{~m}$; concrete modulus of elasticity $E=37500 \mathrm{MPa}$; Poisson ratio $v=0.20$; mass intensity of slab $\mu=\rho \cdot h=2500 \cdot 0.24=600 \mathrm{~kg} / \mathrm{m}^{2} ;$ damping angular frequency $\omega_{b}=0.1 \mathrm{rad} / \mathrm{s}$. The layers of foundation $2 \div 5$ are included in computational model as Winkler elastic foundation. The modulus of foundation compressibility $K$ was varied in interval $50 \div 500$ $\mathrm{MN} / \mathrm{m}^{3}$. In the interval $50 \div 200 \mathrm{MN} / \mathrm{m}^{3}$ with the step $25 \mathrm{MN} / \mathrm{m}^{3}$ and in the interval $200 \div 500$ $\mathrm{MN} / \mathrm{m}^{3}$ with the step $50 \mathrm{MN} / \mathrm{m}^{3}$.

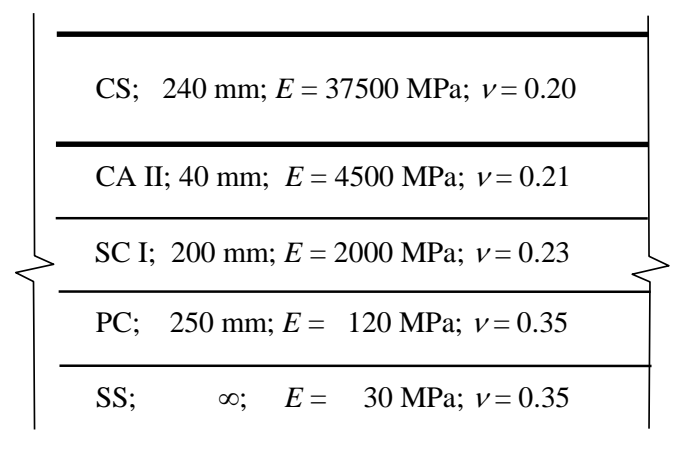

Fig. 2. Composition of pavement.

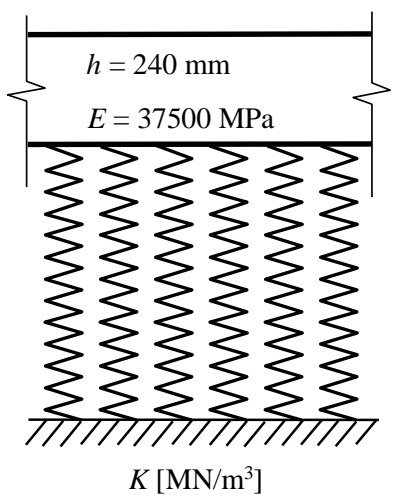

\section{Numerical solution and obtained results}

The synchronous vibration of the system vehicle - slab is mathematically described by the system of three $2^{\text {nd }}$ order ordinary differential equations. Two equations (1) describe vibration of vehicle and one equation (6) describes vibration of the slab. All numerical calculations and displaying of obtained results were realised in MATLAB [2]. The $4^{\text {th }}$ order Runge Kutta step-by-step integration method was used for numerical solution.

Initial conditions are also part of the solution. It is assumed that the slab is at the beginning of the solution motionless. Initial conditions on the vehicle are considered in 2 variants. 
Variant 1 - vehicle springs are lighten, mass point amplitude is up oriented from equilibrium position. Initial conditions are as follows: $r_{1}(0)=0.02 \mathrm{~m} ; r_{2}(0)=0.002 \mathrm{~m} ; \dot{r}_{1}(0)$ $=0.0 \mathrm{~m} / \mathrm{s} ; \dot{r}_{2}(0)=0.0 \mathrm{~m} / \mathrm{s}$;

Variant 2 - vehicle springs are aggravated, mass point amplitude is down oriented from equilibrium position. Initial conditions are as follows: $r_{1}(0)=-0.02 \mathrm{~m} ; r_{2}(0)=-0.002 \mathrm{~m} ; \dot{r}_{1}$ $(0)=0.0 \mathrm{~m} / \mathrm{s} ; \dot{r}_{2}(0)=0.0 \mathrm{~m} / \mathrm{s}$;

It was considered with the speed of vehicle motion $V=75 \mathrm{~km} / \mathrm{h}$. Numerical solution was realized in dependence on the modulus of foundation compressibility $K$. For every value of $K$ the time course of middle slab vertical displacements and the time course of contact force were calculated. Maxima of middle slab vertical displacements and dispersion of contact forces are plotted versus modulus of foundation compressibility $K$. Demonstration of obtained results for Variant 1 is presented in Fig. 3, 5, 6 and for Variant 2 in Fig. 4, 7, 8.

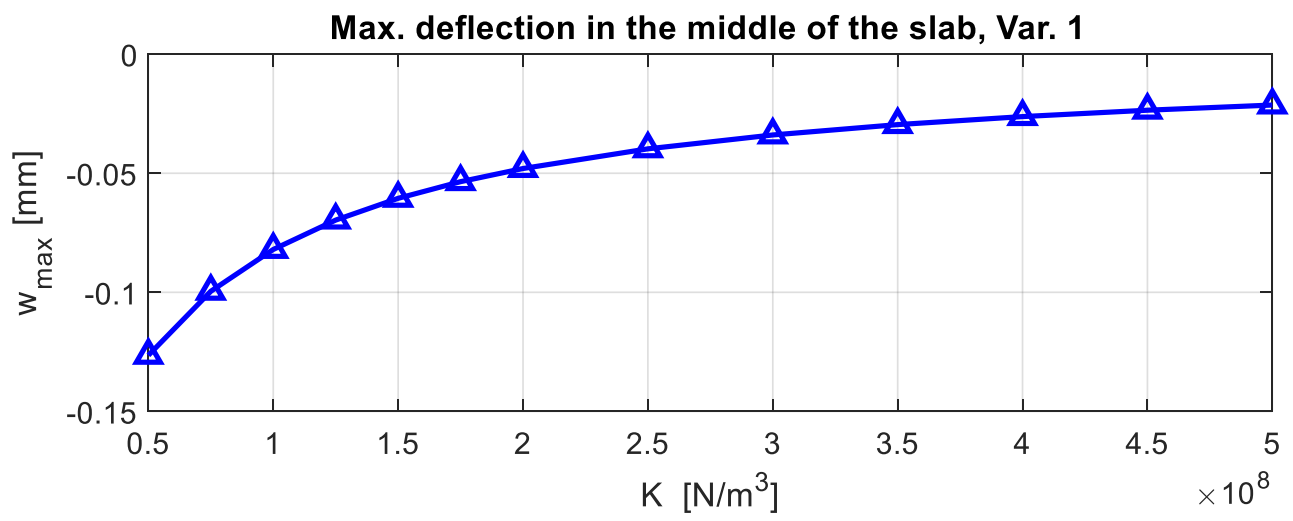

Fig. 3. Variant 1, maxima of middle slab deflection $w_{\max }$.

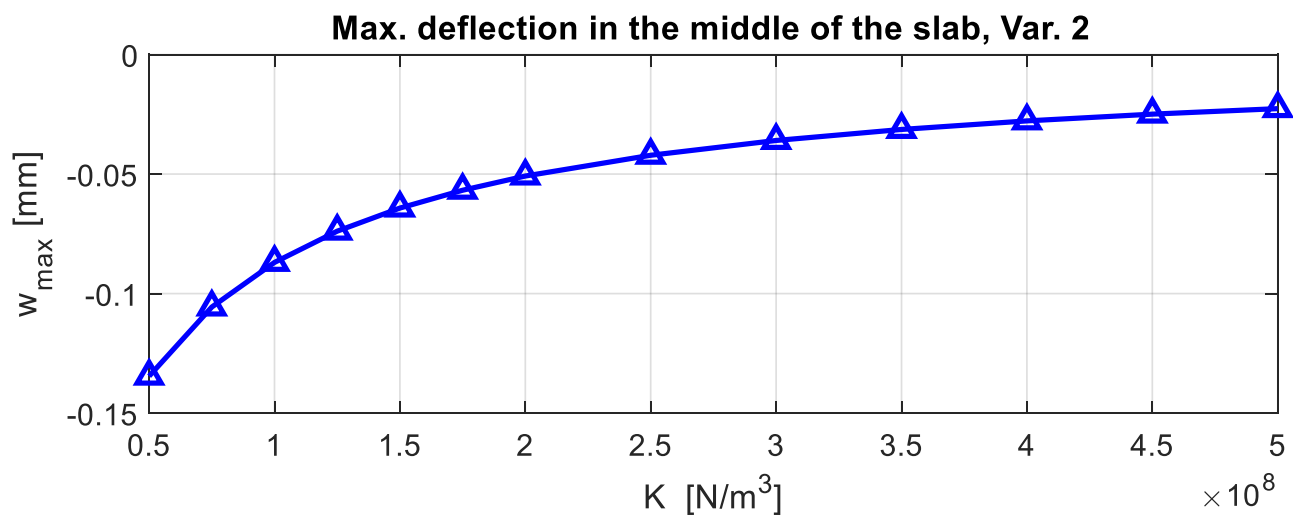

Fig. 4. Variant 2, maxima of middle slab deflection $w_{\max }$. 


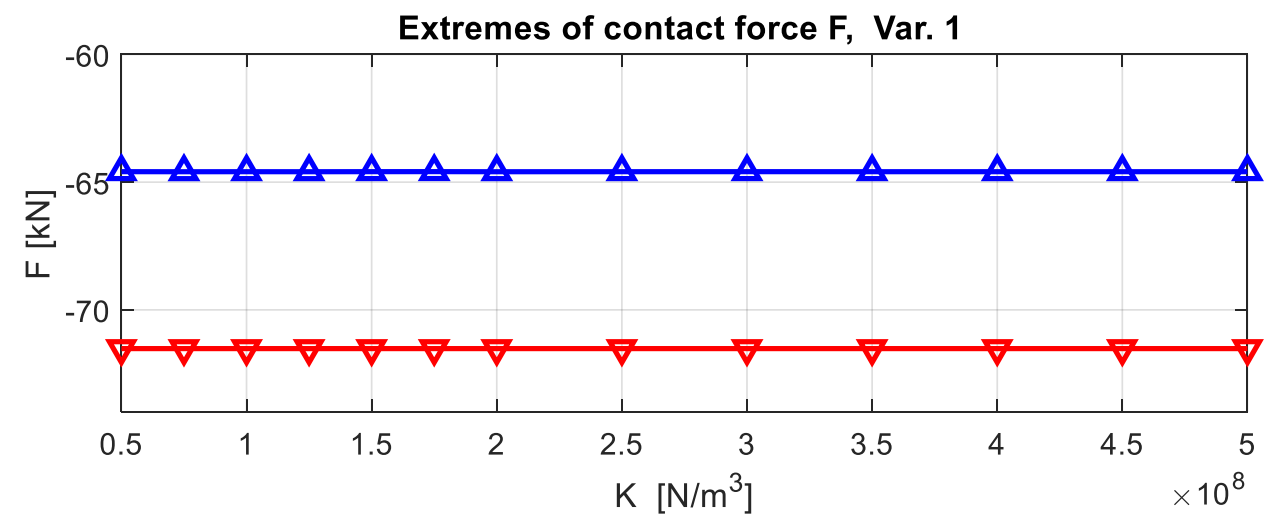

Fig. 5. Variant 1, extremes of contact force $F$.

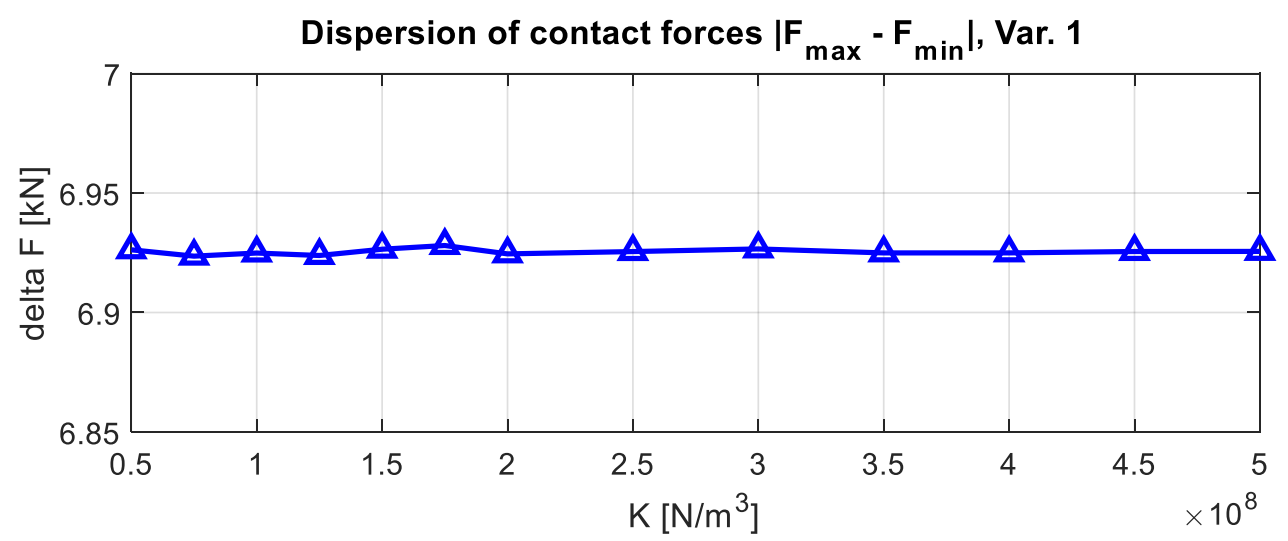

Fig. 6. Variant 1 , dispersion of contact forces $\left|F_{\max }-F_{\min }\right|$.

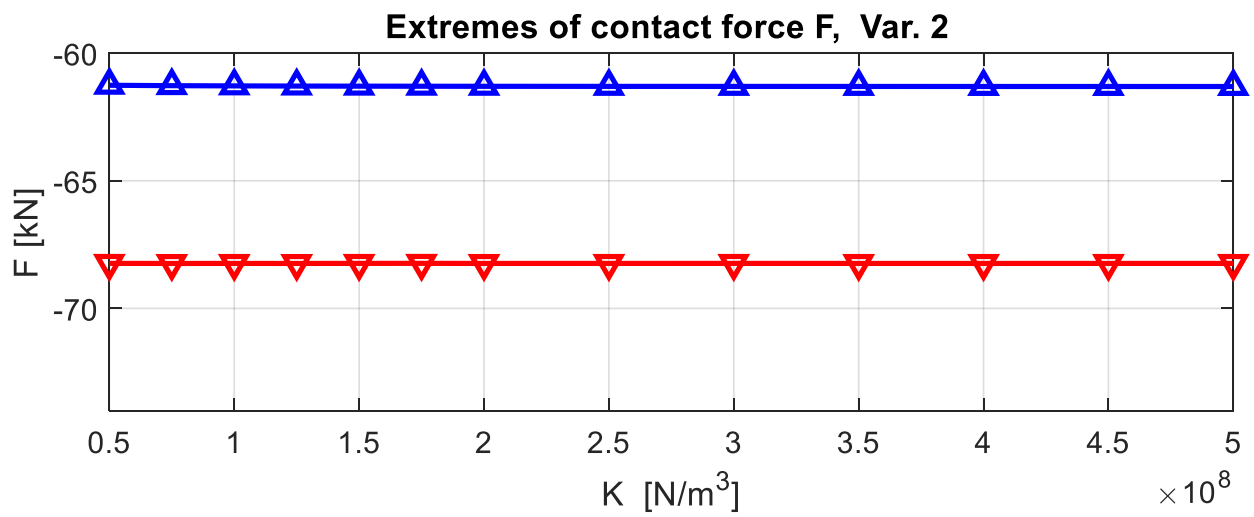

Fig. 7. Variant 2, extremes of contact force $F$. 


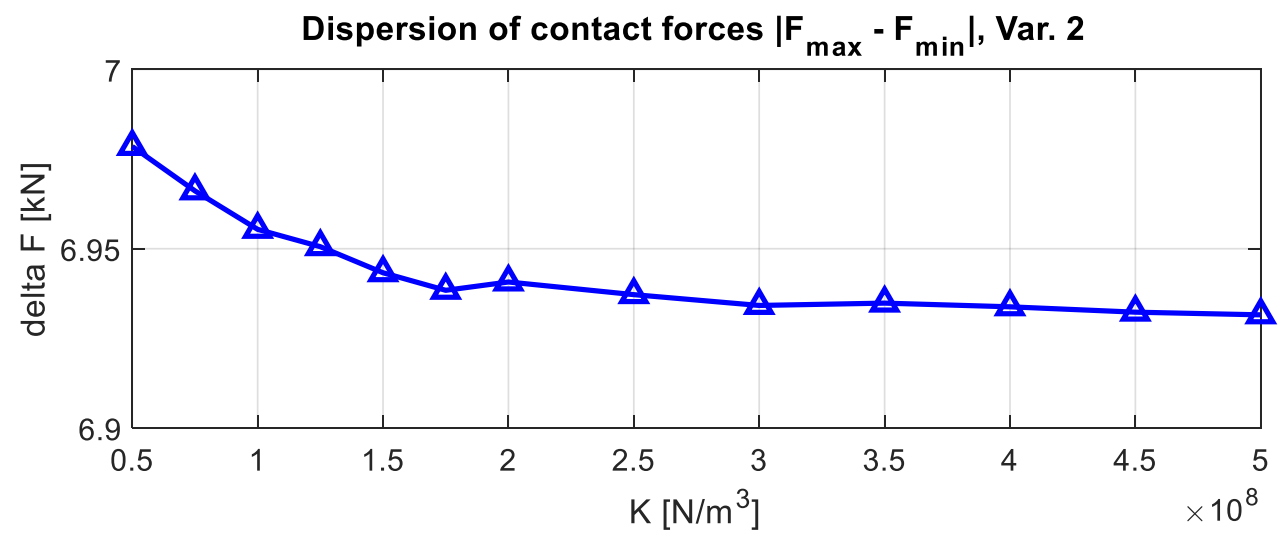

Fig. 8. Variant 2, dispersion of contact forces $\left|F_{\max }-F_{\min }\right|$.

\section{Conclusion}

Modulus of foundation compressibility greatly affects plate deflections. The initial conditions on the vehicle practically do not affect this value. In Variant 1, the deflection varies within the range of $0.126 \div 0.021 \mathrm{~mm}$ and for Variant 2 within the range of $0.134 \div 0.022 \mathrm{~mm}$. Changing the modulus of foundation compressibility practically does not affect the contact forces. From an engineering point of view, the initial conditions on the vehicle do not affect the dispersion of contact forces. We are still moving between $6.978 \div 6.931 \mathrm{kN}$. The only change is that in Variant 1, we move at loading levels of approximately $64 \div 71 \mathrm{kN}$ and in Variant 2 at loading levels of approximately $61 \div 68 \mathrm{kN}$.

This work was supported by the Grant National Agency VEGA of the Slovak Republic, project number $1 / 0006 / 20$.

\section{References}

1. J. Melcer, et al., Dynamics of transport structures (EDIS, Žilina, 2016, in Slovak)

2. J. Melcer, G. Lajčáková, Application of program system MATLAB for the solution of the structural dynamics problems, (EDIS, Žilina, 2011, in Slovak)

3. D. Kuchárová, G. Lajčáková, Procedia Engineering, 190 (2017)

4. L. Frýba, Vibration of Solids and Structures under Moving Load (ACADEMIA, Praha, Noordhoff International Publishing, Groningen, 1972) 